\title{
Variations in Weight Control Behaviors and Body Image Dissatisfaction Among Preadolescents in a Low-Income Community in Fresno, California
}

\author{
Lisa Herzig, Amber Hammons, and Shelly Matson \\ California State University, Fresno
}

\begin{abstract}
Purpose: This study sought to determine whether healthy, overweight, and obese preadolescents living in low-income neighborhoods differ in regards to body image and weight control behaviors. It is critical to identify early precursors to body image issues so that optimal prevention programs can be implemented. Subjects: The sample consisted of 64 preadolescents ages 8 to13 years, including 29 male (45\%) and 35 female (55\%) fourth, fifth, and sixth graders living in low-income neighborhoods in Fresno, California. Measures: (a) Height and weight were measured to calculate BMI-for-age $\left(\mathrm{kg} / \mathrm{m}^{2}\right)$, and (b) the CDC 13question Body Image Survey was administered. Analysis: ANOVA was used to compare differences in body image and weight control behaviors by weight category (healthy, overweight, obese).Results: The obese group reported more body image dissatisfaction than did the healthy and overweight groups. Obese preadolescents were less happy with their body image and dieted more than healthy weight preadolescents. Overweight preadolescents were more similar in behaviors to healthy weight preadolescents than obese preadolescents. Conclusions: Low self-esteem related to weight may be exacerbated in the adolescent years when new pressures and challenges emerge. Targeting preadolescent overweight and obese individuals with body image issues may be useful in ameliorating some of the problems that are magnified in adolescence, such as dieting and eating disorders.
\end{abstract}

(C) 2013 Californian Journal of Health Promotion. All rights reserved.

Keywords: Body Image, Adolescents, Overweight, Body Dissatisfaction, Obesity, Preadolescent Dieting

\section{Introduction}

Over the past two decades the prevalence of overweight and obese children and adolescents has reached epidemic proportions in the United States (Wang, Liang, \& Chen, 2009; Mirza, Mackey, Armstrong, Jaramillo, \& Palmer, 2011; Krauss, Powell, \& Wada, 2012). The National Health and Nutrition Examination Survey (NHANES) from 2007 to 2008 showed 16.9\% of 2- to 19-year-olds to be overweight or obese (Singh, Mulder, Twisk, Van, \& Chinapaw, 2008; Ogden \& Carroll, 2010). Minorities are disproportionally affected with $29 \%$ of nonHispanic Black and $17.5 \%$ of Hispanic adolescent girls classified as obese, compared to only $14.5 \%$ of non-Hispanic White adolescent girls (Krauss et al., 2012). Childhood and adolescent obesity can be physically and emotionally challenging, especially in a society consumed with thinness. Overweight and obese children are at increased risk for a plethora of physical and psychological concerns (World Cancer Research Fund, 2007).

Minority obese youth have greater body dissatisfaction, which places them at increased risk for depression and disordered eating (Stice \& Whitenton, 2002; Wang et al., 2009). This association between body dissatisfaction and disturbed eating (Perez \& Joiner, 2003) can perpetuate weight problems. According to social comparison theory, as overweight and obese individuals compare their body size and weight to others whom they believe to possess a desirable body size and weight, they behave in ways to achieve that body size and weight, thus affecting how they feel and think about their own body size, weight, and shape. They then begin to internalize what social comparison theory calls "reflected appraisals", the adoption of the desirable characteristics of those they admire and begin to adopt them for themselves (Xie et al., 2010). This concept may explain why overweight individuals may be a greater risk for 
"negative psychological” outcomes such as depression and a negative body image.

Latino youth are at a higher risk for body image dissatisfaction because of the higher prevalence of obesity in their culture. Mirza discovered that the higher the BMI, the lower the self-esteem, the stronger the desire to be thinner, and higher levels of body dissatisfaction (Mirza et al., 2011). Overweight and obese 11- and 12-year olds were more likely to practice calorie restriction and unhealthful dieting practices than their non-overweight counterparts in the hope of losing weight (Boutelle et al., 2001; Burrows \& Cooper, 2002; Field et al., 2003).

In a similar vein, the extent of overweight has an influence on both social and psychological development. Obese children have higher odds of being bullied than do overweight children (Lumeng et al., 2010). Obese children have also demonstrated poorer academic performance compared to non-obese children (Gable, Krull, \& Chang, 2012). Body image perceptions are also related to weight control practices over time. Normal-weight adolescents who perceive themselves as being overweight are more likely to use unhealthful weight control strategies such as eating less food and vomiting to keep from gaining weight (Ursoniu, Putnoky, \& Vlaicu, 2011).

Based on research findings, it is critical to identify early precursors to body dissatisfaction, low self-esteem, and eating disorders before these behaviors are fully expressed in adolescence. Studies have established that adolescents that used harmful weight control practices increased their BMI and were at a greater risk for becoming overweight compared to those that did not use unhealthy behaviors (Neumark-Sztainer et al., 2006). Understanding at-risk populations can help health practitioners develop effective intervention strategies to assist overweight and obese children and preadolescents develop positive body image within the context of obesity status and cultural beliefs. This research is especially needed in lower-income populations, since children from lower socioeconomic backgrounds are more likely to be overweight, participate in harmful dieting practices such as skipping meals, and be less receptive to healthy weight control advice (O’Dea et al., 2001).

\section{The Present Study}

The purpose of this study was to examine BMI in relation to body image in preadolescents in a low-income community in Fresno, California (Dahlberg, Toal, Swahn, \& Behrens, 2011). It was hypothesized that overweight and obese preadolescents would have more body image dissatisfaction than preadolescents with healthy weights. Overweight and obese preadolescents were predicted to show more concern than healthy weight preadolescents with managing their weights through dieting behaviors.

\section{Methods}

\section{Sample}

Participants were residents of Susan B. Anthony and Lowell neighborhood in Fresno, California. Both were chosen due to the high poverty level. The sample consisted of 29 males (45\%) and 35 females (55\%), all in Grades 4, 5, or 6 (ages 8 to 13 years), residing in a low-income neighborhood in Fresno, California. Students were between 9 and 12 years old with one 13 year old male. There were 5 African Americans, 7 Caucasians, 21 mixed race, 23 Hispanic, and 6 undisclosed. This population was fairly representative of students living in the targeted neighborhoods. The Fresno community in which the study population was recruited is considered one of the most severely impoverished neighborhoods in the community, with an estimated $49.1 \%$ living below the poverty line of $\$ 15,219.00$ annual income for a family of three (City of Fresno. The Lowell Project page).

\section{Design and Procedure}

This study was approved by the Institutional Review Board at California State University, Fresno. Recruitment occurred during parentteacher meetings and open houses. Interpreters were used to ensure comprehension and surveys were administered in English and Spanish. The school provided a frozen dessert as an incentive to help increase the number of returned consent forms. Two California State University, Fresno undergraduate students who had been previously 
recruited by the graduate student from an undergraduate nutrition class were present to help with the study. The surveys were handed out to the participants; both English and Spanish forms were given. The body image surveys were anonymous and completed by participants individually. The surveys were given to the students over a two-day period during scheduled physical education classes. Only those students who had consent forms signed by parents were given the body image survey. The graduate student monitored the survey administration to ensure all questions were answered. On average it took the students 15 minutes to complete the body image survey.

Finally, study participants removed their shoes, and height and weight measurements were taken in an area away from the others. One trained undergraduate student measured height using a stadiometer; A different trained undergraduate student took the weight using a digital scale. Additionally, qualified physical education teachers, assisted with height and weight measurements, and used the same equipment and standard protocol for all measurements.

\section{Measures}

$B M I$. Measures of height and weight were used to calculate BMI-for-age $\left(\mathrm{kg} / \mathrm{m}^{2}\right)$. CDC body image survey. The 13-item CDC body image questionnaire assessed participants' perceptions of their bodies as well as their dieting behaviors (Dahlberg et al., 2011). Only six questions directly regarding body image and dieting were used in this study. A sample item regarding dieting was, "Have you ever dieted to lose weight?” A sample item regarding body image was, "Are you happy with your body image?" Items were scored on a 5-point linear scale (1 = never to 5 = always).

\section{Analysis}

Analysis of variance (ANOVA) was used to compare BMI groups based on responses to individual body image and dieting questions. Participants were categorized as normal $(<85$ th percentile), overweight ( $>$ 85th to $<$ 95th percentile), or obese ( $>$ 95th percentile) based on CDC guidelines (Ogden, Carroll, Curtin, Lamb, \& Flegal, 2010). All data were analyzed using
SPSS (version 18.0, 2010, SPSS Inc., Chicago, IL). For significance, $p \leq .05$ was considered significant and $p \leq .10$ was considered marginally significant. Multivariate analyses were not possible to conduct due to the low sample size.

\section{Results}

Forty-five percent of the sample was classified as healthy weight, $22 \%$ as overweight, and $33 \%$ as obese (Table 1). With regard to happiness with one's body image, the hypothesis was partially supported, $\left(F_{(2,61)}=4.38, p<.02\right)$. Pairwise comparisons revealed that obese preadolescents were significantly less happy with their body image $(\underline{M}=2.91)$ than healthyweight preadolescents $(\underline{M}=3.93, p=.005)$. There were no significant differences between overweight and healthy-weight preadolescents on happiness with body image, but a trend suggested that obese preadolescents were less happy with their body image than overweight preadolescents $(\underline{M}=3.64, p<.10)$.

\section{Table 1}

\section{Gender and Grade Frequencies by Weight} Status

\begin{tabular}{lrrr}
\hline & $\begin{array}{r}\text { Healthy } \\
(\mathrm{n}=29)\end{array}$ & $\begin{array}{r}\text { Overweight } \\
(\mathrm{n}=14)\end{array}$ & $\begin{array}{r}\text { Obese } \\
(\mathrm{n}=21)\end{array}$ \\
\hline $\begin{array}{l}\text { Gender } \\
\text { Male }\end{array}$ & $12(41.4 \%)$ & $11(78.6 \%)$ & $6(28.6 \%)$ \\
Female & $17(58.6 \%)$ & $3(21.4 \%)$ & $15(71.5 \%)$ \\
Grade & & & \\
4 & $11(37.9 \%)$ & $2(14.3 \%)$ & $4(19.0 \%)$ \\
5 & $14(48.2 \%)$ & $7(50.0 \%)$ & $9(42.9 \%)$ \\
6 & $4(13.8 \%)$ & $5(35.7 \%)$ & $8(38.1 \%)$ \\
\hline
\end{tabular}

With regard to dieting behaviors (Table 2), specifically, counting calories, there was a trend toward differences among the three weight categories $(F(2,61)=2.55, p<.10)$. Obese preadolescents $(\underline{M}=2.33)$ reported counting calories more than did healthy-weight preadolescents $(\underline{M}=1.66)$ and overweight preadolescents $(\underline{M}=1.57)$. Differences in purchasing diet food were marginally significant $(\mathrm{F}(2,61)=2.75, p=.07)$, with obese preadolescents $(\underline{M}=2.62)$ reporting purchasing more diet food than healthy $(\underline{M}=1.86)$ or overweight $(\underline{M}=1.86)$ preadolescents. There was a significant difference among groups in dieting to lose weight $(\mathrm{F}(2,61)=5.55, p=.006)$, 
with obese preadolescents dieting more $(\underline{M}=$ 2.76) than healthy-weight preadolescents $(\underline{M}=$ $1.69, p<.005)$, and overweight preadolescents $(\underline{M}=1.86, p<.05)$. There were no differences among groups on discussing dieting with friends and family.

Table 2

\begin{tabular}{lrrr}
\multicolumn{4}{c}{$\begin{array}{c}\text { Mean Body Image and Dieting } \\
\text { Behaviors by Weight Status }\end{array}$} \\
\hline & $\begin{array}{r}\text { Healthy } \\
(\mathrm{n}=29) \\
\mathrm{M}(\mathrm{SD})\end{array}$ & $\begin{array}{r}\text { Overweight } \\
(\mathrm{n}=14)\end{array}$ & $\begin{array}{r}\text { Obese } \\
(\mathrm{n}=21) \\
\end{array}$ \\
\hline Happy with & 3.93 & 3.64 & $\mathrm{M}(\mathrm{SD})$ \\
\hline image & $(1.13)^{*}$ & $(1.45)$ & $(1.18)^{*}$ \\
\hline Count & 1.66 & 1.57 & 2.33 \\
calories & $(1.05)^{*}$ & $(1.16)$ & $(1.35)^{*}$ \\
\hline Buy diet & 1.86 & 1.86 & 2.62 \\
food & $(1.25)^{*}$ & $(1.10)$ & $(1.24)^{*}$ \\
Dieted to & 1.69 & 1.86 & 2.76 \\
lose weight & $(.89)^{*}$ & $(1.03)^{*}$ & $(1.51)^{*}$ \\
\hline Discuss & 2.55 & 2.86 & 2.76 \\
dieting & $(1.57)$ & $(1.61)$ & $(1.41)$ \\
\hline
\end{tabular}

*Denotes difference between groups, but always in the direction of obese>overweight and obese>healthy. No differences were found between healthy and overweight

\section{Discussion}

This study evaluated participants' dieting behaviors and their perceptions of their body image. Obese preadolescents reported more dieting behaviors and more dissatisfaction with their body image, but in this sample, overweight preadolescents' perceptions of body image and reported dieting behaviors more closely resembled those of the healthy-weight preadolescents. This is significant because it suggests that moving from obese to overweight alone potentially offers great benefits to the preadolescent's body image and dieting behaviors. This is consistent with other studies that have found that the more obese the adolescent, the larger the impact on body image (e.g. In-iw , Manaboriboon, Chomchai, 2010; Mirza et al, 2011).

This information may be useful in future interventions with preadolescents in this geographical area. Targeting overweight preadolescents may help them to lose or maintain their weights so their self-esteem is not further affected in adolescence. For obese preadolescents, timely intervention to help lose weight is imperative. Some research suggests that dieting during adolescence is not effective and may even be associated with weight gain (Field et al., 2003; Neumark-Sztainer et al., 2006). Interventions should emphasize physical activity as well as healthful eating as a means to lose weight. A recent study found that overweight and obese children's energy intake in comparison to their healthy weight peers varied based on age, with overweight and obese children under age six reporting higher energy intake and those older than six to 10 reporting lower energy intake (Skinner, Steiner, \& Perrin, 2012). Early interventions may consider emphasizing caloric intake, and interventions with older children, physical activity (Skinner et al., 2012).

\section{Limitations}

The small sample size limited the generalizability of the findings, as well as the ability to run more complex analyses to control for potential confounding variables. Nevertheless the fact that some findings were significant suggests areas that warrant further study.

\section{Conclusion}

While further research is needed, the findings of this study provide a basis to strategize and develop interventions with overweight and obese preadolescents. Targeting children and preadolescents before they reach adolescence is critical because issues of body image and dieting are typically magnified in middle and high school (Field et al., 2003; Neumark-Sztainer et al., 2006). Therefore, it is ideal to help overweight and obese preadolescents to develop a positive body image, establish healthful weight loss techniques, learn to cope with societal pressures, and resist peer pressure to be thin. Implementing a comprehensive family-based program, including lesson plans and discussionbased sessions focusing on body image acceptance among preadolescents, may be one way to address the issue. 


\section{References}

Babey, S. H., Wolstein, J., Diamant, A. L., Bloom, A., \& Goldstein, H. (2011). A patchwork of progress changes in overweight and obesity among California 5th, 7th, and 9th graders, 2005-2010. Retrieved from http://www.publichealthadvocacy.org/research/ patchworkdocs/OFT\%20brief_final.pdf.

Boutelle, K., Neumark-Sztainer, D., Story, M. \& Resnick, M. J. (2002). Weight control behaviors among obese, overweight, and nonoverweight adolescents. Pediatric Psychology, 27(6), 531-540.

Burrows, A. \& Cooper, M. (2002). Possible risk factors in the development of eating disorders in overweight pre-adolescent girls. International Journal of Obesity Related Metabolic Disorders, 26(9), 1268-1273.

City of Fresno. The Lowell Project page. Retrieved from http://www.fresno.gov/Government/DepartmentDirectory/DCR/NeighborhoodRevitalization/Low ellProject2010.htm.

Dahlberg, L. L., Toal, S. B., Swahn, M., \& Behrens, C. B. (2011). Measuring violence-related attitudes, behaviors, and influences among youths: A compendium of assessment tools (2nd ed.). Retrieved from http://www.djj.state.fl.us/JJDP/Performance_Measurement/Body_Image.pdf

Field, A. E., Austin, S. B., Taylor, C. B., Malspeis, S., Rosner, B., Rockett, H. R., . . \& Colditz, G. A. (2003). Relation between dieting and weight change among preadolescents and adolescents. Pediatrics, 112, 900-906.

Gable, S., Krull, J. L., \& Chang, Y. (2012). Boys’ and girls’ weight status and math performance from kindergarten entry through fifth grade: A mediated analysis. Child Development, 83, 1822-1839.

In-iw S, Manaboriboon B, Chomchai C. (2010). A comparison of body-image perception, health outlook and eating behavior in mildly obese versus moderately-to-severely obese adolescents. Journal of the Medical Association of Thailand, 93(4), 429-35.

Krauss, R. C., Powell, L. M., \& Wada, R. (2012). Weight misperceptions and racial and ethnic disparities in adolescent female body mass index. Journal of Obesity, 2012, 1-9. Lumeng, J. C., Forrest, P., Appugliese, D. P., Kaciroti, N., Corwyn, R. F., \& Bradley, R. H. (2010). Weight status as a predictor of being bullied in third through sixth grades. Pediatrics, 125, 1301. doi:10.1542/peds.2009-0774

Mirza, N. M., Davis, D., \& Yanovski, J. A. (2005). Body dissatisfaction, self-esteem, and overweight among inner-city Hispanic children and adolescents. Journal of Adolescent Health, 36, 267.

Mirza, N. M., Mackey, E. R, Armstrong, B., Jaramillo, A., \& Palmer, M. (2011). Correlates of self-worth and body size dissatisfaction among obese Latino youth. Body Image, 8(2), 173-178.

Neumark-Sztainer, D., Wall, M., Guo, J., Story, M., Haines, J., \& Eisenberg, M. (2006). Obesity, disordered eating, and eating disorders in a longitudinal study of adolescents: How do dieters fare 5 years later? Journal of the American Dietetic Association, 106, 559-568.

O’Dea, J.A. \& Caputi, P. (2001). Association between socioeconomic status, weight, age and gender, and the body image and weight control practices of 6- to 19-year-old children and adolescents. Health Education Research, 16(5): 521-532.

Ogden, C., \& Carroll, M. (2010). Prevalence of obesity among children and adolescents: United States, trends 1963-1965 through 2007-2008. Retrieved from http://www.cdc.gov/nchs/ data/hestat/obesity_child_07_08/obesity_child_07_08.pdf

Ogden, C. L., Carroll, M. D., Curtin, L. R., Lamb, M. M., \& Flegal, K. M. (2010). Prevalence of high body mass index in U.S. children and adolescents, 2007-2008. Journal of the American Medical Association, 303, 242-249.

Perez, M. \& Joiner, T. (2003). Body image dissatisfaction and disordered eating in Black and White women. International Journal of Eating Disorders, 33, 342-350.

Singh, A. S., Mulder C., Twisk, J. W., Van, M. W., \& Chinapaw, M. J. (2008). Tracking of childhood overweight into adulthood: A systematic review of the literature. Obesity Review, 9, 474-488. 
Skinner, A. C., Steiner, M. J., \& Perrin, E. M. (2012). Self-reported energy intake by age in overweight and healthy-weight children in NHANES, 2001-2008. Pediatrics,2012-0605; published ahead of print September 10, 2012. doi:10.1542/peds.2012-0605

Stice, E., \& Whitenton, K. (2002). Risk factors for body dissatisfaction in adolescent girls: A longitudinal investigation. Developmental Psychology, 38, 669-678.

Ursoniu, S., Putnoky, S., \& Vlaicu, B. (2011). Body weight perception among high school students and its influence on weight management behaviors in normal-weight students: A cross-sectional study. Wien Klin Wochenschr, 123(11-12), 327-333.

Wang, Y., Liang, H., \& Chen, X. ( 2009). Measured body mass index, body weight perception, dissatisfaction and control practices in urban, low-income African adolescents. BMC Public Health, 9, 1-12.

World Cancer Research Fund/American Institute for Cancer Research. (2007). Food, nutrition, physical activity, and the prevention of cancer: A global perspective. Washington, DC: American Institute for Cancer Research.

Xie, B., Unger, J. B., Gallaher, P., Johnson, C. A., Wu, Q., \& Chou, C. P. (2010). Overweight, body image, and depression in Asian and Hispanic adolescents. American Journal of Health Behaviors, 4, 476-488.

\author{
Author Information \\ *Lisa Herzig, PhD, RD, CDE \\ California State University, Fresno \\ Department of Food Science and Nutrition \\ Assistant Professor \\ Dietetics Program Coordinator \\ 5300 North Campus Drive M/S FF/17 \\ Fresno, CA 93740 \\ PHONE: 559-278-2043 \\ FAX: 278-8424 \\ Amber Hammons, PhD \\ California State University, Fresno \\ Department of Child Family, and Consumer \\ Sciences \\ Shelly Matson MS, RD \\ California State University, Fresno \\ Department of Food Science and Nutrition \\ * corresponding author
}

